\title{
Aucas en la ciudad de Santiago. La rebelión mapuche de 1723 y el miedo al «otro» en Chile central*/
}

\section{Aucas in the Santiago city. The mapuche rebellion of 1723 and the fear to the «others» in central Chile}

\author{
Hugo Contreras Cruces \\ Universidad Academia de Humanismo Cristiano; \\ Laboratorio de Historia Colonial (PUCCh)
}

En el contexto de la llamada rebelión general indígena de 1723, este artículo reconstituye las acciones llevadas a cabo para reprimir un supuesto ataque rebelde a la ciudad de Santiago en octubre de dicho año, el cual nunca llegó a realizarse, pero que llevó a la cárcel a más de una centena de indios que habitaban en las cercanías de la ciudad, la mayoría de los cuales eran inmigrantes venidos de la frontera del río Biobío o desde el interior de la Araucanía. Dicho proceso se estudia desde la perspectiva del miedo al «otro», en este caso al indígena migrante, portador de un idioma, costumbres y una religiosidad mayormente incomprensibles para los hispanocriollos de Chile central, lo que los convertía inmediatamente en sospechosos y se les calificaba como «aucas»o rebeldes.

PALABRAS CLAVE: Rebelión; Inmigrantes indígenas; Miedo al «otro»; Memoria; «Aucas».

Within the context of the so-called indigenous rebellion in 1723, this article reconstructs the actions carried out to suppress an alleged rebel attack on the city of Santiago in October of that year, an attack which never occurred, but nevertheless brought to jail over one hundred Indians, inhabitants of the nearby city areas, and most of whom were immigrants who had come from the border of the river Biobio or from within the Araucania. This process is studied from the perspective of fear of the "other» who was in this case an indigenous migrant carrying language, customs and religion all of which were mostly incomprehensible to the hispanocriollos of central Chile, thereby making them immediately to appear suspicious and be referred to as «Auca», or rebel.

KEYwORDS: Rebellion; Indian immigrants; Far of the «other»; Memory; «Auca».

* Este artículo es resultado del proyecto Fondecyt, n. ${ }^{\circ}$ 1100215, «La diáspora mapuche en Chile colonial. Migraciones forzadas y voluntarias desde Araucanía hacia el centro y norte de Chile y otras regiones del virreinato peruano (siglos XVI-XVIII)». 


\section{Introducción}

El 30 de septiembre de 1723 el alcalde de primer voto de Santiago de Chile, Pedro Gallardo Lísperguer, abrió una investigación judicial con escasos precedentes en el reino. En ella se vieron involucrados más de ciento veinte indios, muchos de los cuales eran inmigrantes de la Araucanía que habitaban los distritos cercanos a la capital chilena. ${ }^{1}$ Lo anterior se concretó en su encarcelamiento bajo la sospecha de querer atacar la ciudad, delito que aunque había sido frustrado era considerado atroz, pues no solo atentaba contra la vida de las personas, sino también contra la autoridad de la monarquía y la santidad de la religión, toda vez que el clero local estaría entre las potenciales víctimas.

Mientras tanto, en Santiago y sus alrededores la noticia del supuesto alzamiento era transmitida de boca en boca y la población, tanto plebeya como de elite, se hacía presa del temor y la desconfianza contra los indios. Ello, a su vez, tenía un correlato en la toma de medidas concretas para proteger la urbe, como fue el apostamiento de custodia armada en los conventos femeninos y el reforzamiento de las rondas urbanas y rurales antes y después de que el conato rebelde fuera suprimido.

Los inculpados rápidamente fueron calificados como aucaes, voz que se usó frecuentemente para designar a los indios hostiles o a los que se alzaban contra la corona. Sin embargo, dicho concepto de origen quechua pero resignificado en el periodo colonial, portaba mayores complejidades. Giudicelli manifiesta que tal categoría operaba como un marcador de la barbarie fronteriza, por la cual los individuos así significados se encontraban alejados tanto del cristianismo como de la civilización. ${ }^{2}$ Particularmente los jesuitas, según lo plantea Valenzuela, no dejaban de manifestar que los indios de la frontera «civilizados» a medias, entre ellos los que arribaban a Chile central, en cualquier momento podían transformarse en aucaes, generándose un paradigma epistémico que equiparaba «no civilizado» con «infiel». Lo anterior aportaba a construir la representación de un «otro» que era eminentemente sospechoso por su origen y conductas. ${ }^{3}$

Ese «otro» era aquel que pertenecía a un universo cultural, social y religioso distinto al propio a la vez que incomprensible, el cual si bien podía ser

1 Sobre los migrantes mapuches en Chile central: Jara, 1959; Videla, 2004, 285-313; Contreras, 2006, 7-32.

2 Giudicelli, 2006, 163.

3 Valenzuela, 2011, 76. 
necesario como mano de obra, no se podía confiar en él y era el primero del que se debía dudar. ${ }^{4}$ Era ese sujeto venido de la llamada «tierra adentro» que había llegado a Chile central como esclavo durante el siglo XVII o, paralelamente, inmigrando voluntariamente durante dicha centuria y en los años posteriores, quien si bien podía ser fenotípicamente parecido a sus congéneres del territorio pacificado, portaba un idioma que muchos ya no hablaban, formas de vida y costumbres que resultaban extrañas o rechazadas por los hispanocriollos, y que al estar exento de tributo, no tener bienes y pocas veces una familia, podía moverse libremente por los parajes rurales del reino. ${ }^{5}$

Por lo anterior, estas líneas junto con reconstituir los hechos que rodearon la represión del supuesto asalto indígena contra Santiago, pretenden introducirse en el estudio de las representaciones del miedo y auscultar, bajo esa perspectiva, como se fue constituyendo tanto un escenario rebelde como un grupo de acusados que no sólo parecían condenados de antemano, sino que en el imaginario social de la época representaban la personificación del temor, la desconfianza y el peligro inminente. ${ }^{6}$ En tal contexto, salían a la luz viejos temores, aquellos que llevaban la guerra a los territorios que, supuestamente, habían estado de paz desde 1558. Pero esto distaba de ser cierto, al menos desde el punto de vista de las representaciones del miedo y de la memoria de tales hechos, que formaban parte del acontecer infausto, como calificó Mellafe a la serie de situaciones y sucesos trágicos que eran frecuentes en Chile y que, según su planteamiento, habrían ayudado a moldear el carácter de los chilenos. ${ }^{7}$ No obstante, terremotos, maremotos, plagas y epidemias tenían un status distinto al de la guerra, pues aun cuando fueran considerados un castigo por las malas acciones de los hombres o el despliegue destructivo de la naturaleza, cada uno de ellos difícilmente se podía predecir. Sólo cabía reaccionar. La guerra, en cambio, era hecha por otros hombres. Sujetos que en el tiempo habían demostrado una conducta pérfida, más aun cuando invitaban a los indios de paz a sumarse a sus alzamientos. ${ }^{8}$

4 Delumeau, 2002, 71.

5 Sobre la visión europea del otro indígena: Todorov, 1987; Pino y Lázaro (coords.), 1995; Weber, 2007.

6 El estudio historiográfico del miedo tiene un importante referente en la obra de Delumeau ya citada. Para el Perú se han compilado una serie de estudios que abordan dicha perspectiva: Rosas (ed.), 2005; en Chile: Valenzuela, 2007, 28-65 y León; 2007, 67-90.

7 Mellafe, 1986, 279-288.

8 Ruiz reconstruye de forma descriptiva y general una serie de momentos en que se temió la extensión de la violencia indígena por Chile central. Ruiz, 1999, 80-94. 
No obstante lo anterior, el proceso que pretendemos reconstituir ha recibido escasa atención de la historiografía, que sólo ha destacado que habrían sido rumores con poco fundamento y hechos que nunca sucedieron. Asumiendo un punto de vista historicista es complejo cuestionar tales argumentos, pues en concreto si es que hubo una concertación indígena para rebelarse, ésta fue desarticulada antes de su concreción, por lo que a lo más habría que destacar la eficiencia de los oficiales de justicia que asumieron tal tarea, como lo hicieron Diego Barros Arana y Miguel Luis Amunátegui. Éstos coincidieron en que el apresamiento de numerosos indios y su posterior juicio fueron reacciones exageradas, pues nunca se encontraron pruebas de un verdadero conato rebelde y sólo se trató de confusiones y sustos infundados. ${ }^{9}$ Posteriormente, Holdenis Casanova en el marco de la historia de las relaciones fronterizas, se hace parte de estas interpretaciones y sólo agrega que a pesar de todas las medidas tomadas la alarma era infundada y, más aún, que ello era parte de la psicosis tremendista que rodeaba los asuntos de la frontera. ${ }^{10}$

Pero más allá del tiempo en que escribieron, dichos autores al hacer una interpretación positiva de los hechos no tomaron en cuenta que las noticias que agitaban a la población santiaguina tenían un origen más profundo que una ingenua credulidad. No comprendieron que el temor al alzamiento y a la traición de los indios locales o de los inmigrantes mapuches, se constituía entre los no indígenas como un sentimiento permanente aunque casi imperceptible en lo cotidiano, el que asomaba con fuerza en situaciones de crisis, como el alzamiento de 1723, y se expresaba violentamente. $\mathrm{Al}$ asumir dicho punto de vista, pasaron por alto el proceso judicial que se sustanció por aquello, el que llevó a más de un centenar de indios a la cárcel, algunos por varios años, muchos más de lo que duró la propia rebelión que originó, en la coyuntura, su prisión.

\section{La memoria del miedo}

Las habladurías que llevaron a la cárcel a tales indios habían circulado por Santiago casi desde el momento mismo en que se supo la noticia de que las parcialidades del sur del río Biobío se habían alza-

9 Barros Arana, 1886, VI, 39-40; Amunátegui, 1910, II, 433-439.

10 Casanova, 1987, 19. 
do. ${ }^{11}$ Lo anterior sucedió en marzo de 1723 y desde el mes siguiente tropas y pertrechos se movilizaron hacia la frontera. Mientras tanto, en la capital el Cabildo discutía la pertinencia de dejar la ciudad sin resguardo, más aun cuando el gobernador insistía en que se le enviaran todos los refuerzos posibles. Tal discusión se producía en el contexto de la firme creencia de que los indios de los alrededores y los que habitaban los partidos cercanos podían estar implicados en el alzamiento. No obstante, ¿había realmente alguna razón para la preocupación de los ediles o aquello solo era parte de la psicosis colectiva que producía la guerra en curso?, ¿es posible encontrar algunos antecedentes o situaciones similares en el pasado que expliquen dichos rumores?, ¿se estaba frente a un temor coyuntural o estas habladurías representaban, al menos en algún punto, una memoria del miedo que salía a la luz ante la eventualidad del peligro? Dichas preguntas guiarán esta primera parte de la búsqueda, pues antecedentes dispersos en distintas fuentes permiten plantear que los rumores antedichos tenían raíces más profundas que la simple coyuntura.

Al mismo tiempo, la construcción de una memoria colectiva del miedo, aun cuando estaba basada en una sucesión de hechos ocurridos en el pasado, no era necesariamente una reproducción actualizada del mismo. Aun más, parecía tratarse de la reconstitución de situaciones significativas traspasadas de generación en generación mediante recuerdos y relatos orales, pero que al mismo tiempo se alimentaban de otras que podían identificarse con lo cotidiano, como era la permanente llegada de migrantes mapuches a los territorios del valle central y su continuo desplazamiento en busca de trabajo. Ello hablaba de cómo eran significados ciertos sujetos y con qué conductas se les asociaba y se les había identificado durante largas décadas.

Desde el punto de vista del relato y aun del proceso judicial, dicha memoria del miedo parecía guiar la causa que se sustanció contra los supuestos rebeldes de Chile central en 1723. Las acusaciones que se les

11 Según O’Phelan, en sociedades extensamente analfabetas el rumor juega un papel preponderante. Éste se divulgaba con facilidad en los lugares públicos, más aun cuando había bases para sostenerlo y pocos recursos para desmentirlo. La información inicial podía sufrir increíbles transformaciones al pasar de boca en boca y es muy difícil definir dónde se iniciaba y dónde terminaba. O'Phelan, 2005, 125. Por su parte, Salinas afirma que en la sociedad tradicional, caracterizada por fuertes relaciones interpersonales, el chismorreo era un canal imprescindible de información, que con el tiempo se transformará en una suerte de espejo valórico de la sociedad. En tal sentido, era frecuente que la extensión de las murmuraciones se usara para sembrar el rechazo hacia los involucrados en ellas. Salinas, 2000, 134-135. 
hicieron, las preguntas que a partir de las mismas se sucedieron y la constitución de una suerte de versión oficial no nacían solo de lo dicho en los interrogatorios o de la imaginación paranoica de los funcionarios y autoridades monárquicas encargados de la sustanciación del proceso. Por el contrario, en una cuota importante aunque imposible de medir, se basaban tanto en los hechos significativos a los que nos hemos referido más atrás, como en la forma en que los mapuches hacían la guerra, la que incluía una serie de acciones necesarias para comenzar y desplegar el conflicto, constituyéndose como uno de los más conocidos la entrega de la llamada «flecha de la guerra». Ésta bien podía ser una flecha ensangrentada o el despojo humano de un enemigo, como su cabeza o una mano, la que era trasladada por un mensajero de un asentamiento a otro, o de persona a persona, intentando que fuera cogida por los posibles destinatarios, que con tal acto aceptaban sumarse a la rebelión. Al contrario la negativa a tomar dicho elemento significaba el explícito rechazo a la iniciativa rebelde.

Otro elemento importante para desencadenar las hostilidades era la convocatoria a grandes fiestas, parlamentos o cagüintunes, denominación que varía según la fuente consultada, entre todos o parte de los involucrados; eventos que, como se supondrá, incluían reuniones y charlas, pero también bailes colectivos y consumo de gran cantidad de alcohol. Dicha institución, a la que los españoles daban el despectivo y generalizado nombre de «borrachera», estaba destinada a constituir alianzas, decidir el conflicto y solidificar los vínculos entre sus participantes.

Junto con la larga tradición guerrera sureña y fronteriza que se remontaba hasta el siglo XVI, parecía ser el alzamiento de 1655 el suceso que marcaba el punto de inflexión en la construcción de la memoria del miedo, particularmente el asociado al levantamiento militar y la serie de dramáticas consecuencias que se derivaban de él. ${ }^{12}$ Quizás el hecho de que en esos momentos efectivamente los indios del norte del Biobío se sumaron a la guerra, que las estancias desde Maule hasta Penco fueran asaltadas y saqueadas y por varios años no pudieron ser repobladas y quienes no qui-

12 Sobre el alzamiento de 1655, véase: Barros Arana, 1885, IV, 481-503. Un episodio anterior, el terremoto de Santiago de 1647, sacó a relucir en toda su crudeza el miedo elitario al otro. Según Valenzuela al desaparecer la disuasión represiva hispana y aprovechando la indefensión de la ciudad, se consideró una posibilidad la constitución de una alianza entre esclavos negros e indígenas, tanto libres como esclavos, para hacer desaparecer la presencia hispanocriolla. Ello tuvo su episodio más dramático en el ahorcamiento público de un esclavo negro, quien reunía los desacatos individuales, políticos y sociales temidos. Asimismo, cundió el temor a que se produjera un alzamiento entre las agrupaciones mapuches de ultra Biobío. Valenzuela, 2007, 33-35. 
sieron rebelarse tuvieron que huir o fueron muertos por los alzados, marcaban este momento del pasado como un modelo al que había que poner atención y que no debía ser olvidado.

Asimismo, la forma en que las noticias del alzamiento traspasaron el Biobío y la incesante presencia de indios de la Araucanía en todos los parajes de Chile central, incluida la ciudad de Santiago, su contacto cotidiano con los habitantes originarios en sus pueblos y en las estancias donde trabajaban y residían, así como la percepción de que cualquier migrante reciente de tierra adentro podía ser un auca, invitaban a las autoridades a estar vigilantes $y$, eventualmente a tomar medidas contra los sospechosos de querer alzarse más allá de los parajes en que la guerra se había hecho cruelmente presente.

Así sucedió en noviembre de 1655 cuando el capitán Diego de Leiva, cabo de las armas del valle de Quillota, recibió noticias de la conspiración de los indios del cercano paraje de La Ligua, quienes supuestamente habían recibido la «flecha de la guerra» y se estaban preparando para levantarse. Ante esto Leiva reunió varias partidas de jinetes armados con órdenes de apresar a los implicados. Según tales informaciones los concertados eran un grupo importante de sujetos, fundamentalmente indios de las diferentes estancias liguanas, los que estaban encabezados por un carpintero llamado Pablo, el cual a pesar de los esfuerzos desplegados por los españoles nunca fue hallado. Asimismo, no se descartaba que los habitantes originarios de lugares colindantes, también estuvieran implicados. ${ }^{13}$

No obstante y a pesar de que se apresaron numerosos indios, mientras otros huyeron del lugar por temor a ser capturados, no quedó nada claro respecto del alzamiento. Con lo anterior, Leiva y sus hombres confirmaron que aunque éste no se produjo, probablemente (quizás así lo pensaron) por la eficiencia de sus medidas, el hecho de que hubiese denuncias con nombre y apellido y que parte de los indios huyeran confirmaba la certeza de la conspiración. Pero más grave que la propia rebelión, era precisamente que la «flecha de la guerra» hubiera llegado hasta territorios tan alejados de su foco original. En tal sentido, era coherente pensar que los indios de parajes situados más al sur podían estar implicados o, al menos, habían hecho la vista gorda ante la presencia de los werken portadores de los símbolos del conflicto. Evidentemente estaba más allá de la jurisdicción de Leiva responder

13 Archivo Nacional Histórico de Chile, Fondo Real Audiencia (ANHRA) 2520, 13, 212-218. Lorenzo Guacalonco, sobre su participación en el alzamiento general de indios. 1655. 
a estas preguntas o tomar medidas frente a ellas, pero la sospecha no dejaba de rondar la cabeza de autoridades y funcionarios civiles y militares.

¿Quiénes eran estos indios? ¿Había forma de identificarlos? ¿Cómo evitar o al menos entorpecer su misión? Eran preguntas que mantenían alerta a los funcionarios, pero también a la población del reino. En ese contexto cada indio era sospechoso, pero quienes habían llegado de la Araucanía lo eran todavía más. ${ }^{14}$ La sospecha generalizada contra los naturales se manifestó claramente en el decreto que dictó el gobernador Antonio de Acuña y Cabrera el 11 de julio de 1655, mediante el cual prohibió las «borracheras» y los juegos de chueca que reunían a los indios de los parajes rurales del reino. Al dictar dicha disposición éste manifestó que era necesaria, pues:

se ha seguido gran disminución de los dichos indios por las muertes que causan las borracheras y juegos de chueca y que si andan vagando se impide el aumento de sus familias; y demás de los daños referidos se han reconocido por averiguaciones constantes que todos los indios naturales deste reino se habían convocado para hacer alzamiento contra la gente española y armas de Su Majestad, pretendiendo hacerse dueños de la tierra y borrar de ella el nombre español y cristiano. ${ }^{15}$

Tal alzamiento se hacía, según el gobernador, a imitación del hecho por los indios de la frontera y de los que residían en las jurisdicciones de Concepción, Chillán e Itata. No obstante, cabe preguntarse si el término imitación se entendía en su sentido lato de seguir el ejemplo de otro para realizar una acción, o bien, con él también se quería significar el comienzo de un proceso donde la comunicación entre los indios del interior del reino de Chile y los alzados era una posibilidad más que cierta. Parecía que algunos de los incidentes registrados aquí y otros cuyo conocimiento no ha llegado hasta nosotros, indicaban que aquello era más que plausible. ${ }^{16}$

Esta medida, que incluía la prohibición de que los indios se desplazaran montados, pues se veía en ello el principal medio de transporte de las

14 Entre 1608 y 1673 la corona autorizó la esclavitud mapuche, sin embargo, desde 1560 éstos eran capturados en sus tierras por soldados e indios amigos y llevados a Chile central y otros lugares del cono sur. Sobre este tema, véase: Jara, 1971, 151-161; Hanisch, 1981, 5-60; Valenzuela, 2009, 225-260.

15 Colección de Historiadores de Chile y documentos relativos a la Historia nacional (CHCh), XXVII, 183. Decreto del gobernador Antonio de Acuña y Cabrera prohibiendo las borracheras y juegos de chueca de los indios. Santiago, 11 de julio de 1655.

16 Este decreto fue vuelto a publicar por el gobernador Francisco de Meneses en 1667. Por su parte, el Sínodo del Obispado de Santiago de 1688 en su capítulo IX, constitución III, con argumentos similares a los del decreto citado confirmó la prohibición de las «borracheras». Colección Tierra Nueva e Cielo Nuevo, IX, 59. 
señales del conflicto, se inscribía en un contexto que junto con haber traspasado lo local para arribar a los altos funcionarios del reino, daba por cierto lo que antes solo era un rumor. De tal modo, desde fines de 1659 la Real Audiencia capitalina insistía en que los habitantes indígenas situados al noroeste de Santiago habían aceptado sumarse a la rebeldía fronteriza, que se extendía por casi cinco años, como bien lo expresó uno de sus fiscales, incluso ampliando la zona geográfica donde el signo del conflicto había llegado, pues según él era verdadero el alzamiento en:

los partidos de Melipilla, Quillota y Aconcagua, pues en los partidos referidos se ha corrido la flecha por los indios alzados, llegando hasta el Guasco y Copiapó. ${ }^{17}$

Por lo tanto, el desplazamiento de algunos indios de ultra Maule durante los años en que la rebelión de mediados del siglo XVII se enseñoreaba de las tierras cercanas a Concepción, sobre todo si cruzaban el río antes referido sin ser acompañados por algún hispanocriollo o sin un salvoconducto válido, los ponía inmediatamente en la mira de las autoridades.

Un sujeto que llenaba todas las características para ser considerado sospechoso e, incluso, algunas más, era Juan Ingaigüeno. Éste era originario de San Cristóbal, uno de los asentamientos rebeldes y si bien se encontraba en Itata al momento en que dicho alzamiento estalló, se unió al mismo junto a los indios locales y, según sus propias declaraciones, anduvo saqueando y maloqueando e incluso ayudó al asesinato de dos indios que no se les quisieron unir. Más tarde y en un periodo aproximado de dos años, Ingaiguieno recorrió longitudinalmente casi todo el reino de Chile, saliendo desde la frontera penquista para llegar hasta la ciudad de La Serena deteniéndose por poco tiempo en algunas estancias de los partidos de Colchagua, Santiago, Aconcagua, Quillota y Choapa. A veces eran meses, otras semanas y hasta unos pocos días los que el indio permanecía en cada lugar, para luego emprender nuevamente su viaje. Todo ello y el hecho que fuera ladino en la lengua castellana y que se dedicara a la curandería, pusieron sobre él una serie de tachas que, en un contexto de desconfianza y sospecha, llevaron a que fuera capturado junto a su mujer cuando se encontraba en la estancia de Rancagua. ${ }^{18}$ 1659.

17 ANHRA, 487, 131 v. El fiscal provisor general a la Real Audiencia de Santiago de Chile.

18 ANHRA, 2668, 1, 1-43. Juan Ingaigüeno. Sumario en su contra por rebelión y espionaje. 1660. 
La captura de Ingaigüeno se produjo a fines de diciembre de 1660, siendo trasladado más tarde a la ciudad de Santiago, donde se continuó el proceso judicial. Sin embargo, lo que más preocupó a los españoles era el hecho que esta situación, lejos de ser un hecho aislado, se sumaba a la captura de otros sujetos de características similares al aprehendido. Más aun, si los indios de estancia o de encomienda que se habían unido a la rebelión seguían siendo definidos como domésticos o yanaconas, haciéndose una distinción tanto política como geográfica de los llamados indios de guerra y de los amigos, asimismo guerreros pero en este caso aliados del Real Ejército. En el caso de Ingaigüeno, su procedencia fronteriza y sus acciones lo enmarcaban dentro del concepto de auca, un indio no solo difícil de sujetar por «naturaleza», sino también pobremente cristianizado y hasta refractario a la palabra evangélica. En tal sentido, no debe extrañar que junto con ser acusado de espía, algunos de los españoles que declararon en el proceso sembraron nuevas dudas sobre él, esta vez respecto de la pureza de sus creencias.

En tal sentido, la acusación de hechicería parecía lógica, más aun cuando Ingaigüeno no tuvo inconvenientes en reconocer su condición de curandero. Pero las plantas y yerbas que reconoció como sus materiales de curación, pronto fueron transmutadas en conjuros y hechizos. Era su palabra contra la de sus acusadores, pues la prueba material de su hechicería - una canastilla donde guardaba los materiales de sus conjuros- no llegó a ser hallada. Asimismo, tampoco era casual que hubiera sido apresado en la estancia de Rancagua, puesto que el corregidor del partido de Colchagua don Alonso de Soto, hacía pocos días había recibido una carta del obispo de Concepción en que lo conminaba a estar vigilante, pues se sospechaba que los rebeldes de Araucanía podían caer de sorpresa al valle central por los pasos cordilleranos que desembocaban en su jurisdicción. ${ }^{19}$

La invasión transcordillerana no llegó a ocurrir y no se tienen antecedentes de que alguna vez se intentara, al menos en la jurisdicción de Colchagua. Sin embargo, en 1658 los habitantes de Cuyo oficiaron al gobernador de Chile pidiendo ayuda, pues según expresaron contaban con información sólida y verificable de que los pewenches y otros grupos étnicos cordilleranos estaban desplazando un importante contingente de guerreros hacia ellos. A raíz de esto, en septiembre de dicho año el corregidor de Cuyo se movilizó con una tropa de españoles hacia el sur y en río Atuel,

19 ANHRA, 2668, 1, $15 \mathrm{v}$. 
a treinta leguas de Mendoza, sorprendió a un grupo de guerreros puelches y pewenches que intentaban llegar hasta el valle de Uco para maloquearlo. Entre los mismos se encontraba un pewenche denominado Ilunculiche, que había protagonizado una maloca en el sector del Maule meses atrás. ${ }^{20}$

Todos los elementos detallados anteriormente llevaban a una sola interpretación, nada favorable para Ingaigüeno, por la cual fue significado como un sujeto que además de ser rebelde, violento y artero, se constituía como la suma de la maldad, la guerra y la perfidia contenida en el alzamiento, incluso más allá de las razones del mismo. En concepto de los españoles, él representaba lo peor de los indios, pero también la forma de operar de los aucaes y por lo tanto, de lo que había que sospechar al encontrarse con sujetos como éste.

Empezaba así la construcción de una memoria del temor, la que afloraría en épocas de crisis pero también como una referencia ante otras situaciones que involucraban el pasado. Tal constructo se hacía presente principalmente en aquellas zonas donde el alzamiento se había concretado y que a raíz del mismo contaban a su haber con muertes de españoles e indios, además de numerosos daños materiales, algunos de los cuales todavía se hacían sentir con fuerza años después que las hostilidades habían cesado. Así se puede apreciar en las palabras de don Fernando Carrión, un estanciero de Itata, quien en 1671, declaró:

\begin{abstract}
que es muy publico y notorio en todo este Reyno de chile como por el alçamiento general que hubo en el de todos los yndios mestiços y los demas yndios amigos que estavan de paz el año de pasado de seisçientos y cinquenta y cinco quedaron todas las estancias desiertas y despobladas de sus dueños yndios y ganados sin haverlas podido bolber a poblar. ${ }^{21}$
\end{abstract}

Situación que precisamente afectaba a la estancia del declarante y que lo había llevado a tribunales, pues dichas tierras consideradas vacías, tendían a ser solicitadas como mercedes por otros españoles.

Asimismo, ante situaciones que - en principio- no tenían mucha relación con la rebeldía indígena, los recuerdos del alzamiento afloraban fácilmente. Así sucedió años más tarde, en 1680, cuando el cacicazgo de Vichuquén fue declarado vacante. Ante ello y entre el tráfago de probanzas de los distintos postulantes y sus testigos, uno de los antecedentes que se

20 Zapater, 1988, 38. de 1671 .

21 ANHRA, 168, 145 v. Declaración de don Fernando de Carrión. Concepción, 17 de enero 
destacó fue la carencia de descendientes del linaje principal del pueblo de indios, pues «...el casique prinçipal a quien de derecho tocare el casicasgo le dieron garrote en este partido quando el alçamiento general...». ${ }^{22}$ Es probable que tal testigo haya conocido al malogrado cacique de nombre don Gabriel, ya que vivía a sólo cuatro leguas del pueblo, por lo cual su testimonio gozaba de la credibilidad necesaria para validarse.

Difícilmente lo anterior era posible para los nacidos tras el alzamiento. Sin embargo, muchas décadas después de sucedido había personas que aun hacían referencia a él para solidificar sus palabras, demostrando cómo operaba la transmisión de los recuerdos y, en esa medida, cómo tales hechos fijaban una memoria del pasado y de los protagonistas del mismo. Será el propio pueblo de indios de Vichuquén el que permita argumentar en este sentido, pues en 1739 otra vez su cacicazgo fue objeto de disputas. Nuevos argumentos y nuevas probanzas fueron presentados, pero los viejos hechos volvían porfiadamente. Así el capitán Pedro Rey, de 69 años, refirió que para el alzamiento de 1655:

fueron castigados algun[os] de la cavesa del motin a quienes dise dicho declarante [a]orcaron y pusieron en cuartos en diversas partes de dicha doctrina y pueblo de bichuquen, y dise dicho declarante no averlo bisto pero que lo save por averse[lo] dicho diversas beses su madre y otras personas asimentadas y naturalisadas en dicha doctrina. ${ }^{23}$

Las palabras de Rey difícilmente podían ser más claras y detalladas, fundamentalmente en lo referido a como se hizo de dicho conocimiento. ${ }^{24}$

Los fantasmas de la rebelión volvieron a despertar en 1715 cuando fue descubierta una supuesta conspiración entre los indios fronterizos y un grupo de caciques de los alrededores de Concepción, motivada por los abusos que los capitanes de amigos y cabos de los fuertes cometían en los tratos comerciales con ellos. Según Barros Arana la mañana del 6 de marzo, día en que se celebraba el Miércoles de Ceniza, había sido elegida por los alzados para asaltar la ciudad; sin embargo, sus intenciones fueron descubierto de 1680

22 ANHRA, 2678, 20, 262. Testimonio del teniente Antonio Fernández. Santiago, 31 de agos-

23 ANHRA, 1686, 4, 260 v. Declaración del capitán Pedro Rey. Peralillo, 12 de noviembre de 1739. Las cursivas son nuestras.

24 Véanse las declaraciones de un expediente de 1706 sobre las tierras de Llico, asimismo situadas en el valle del Itata. Allí los testigos se refirieron al alzamiento de los indios del lugar en 1655, su huída hacia el sur del Biobío y las malocas españolas en las que terminaron capturándolos y esclavizándolos. ANHRA, 1033, 2, 146-266 v. 
tas por el corregidor, quien encarceló a varias decenas de supuestos implicados. ${ }^{25}$ A pesar de que lo cita, la versión del historiador difiere un poco con lo escrito por el navegante francés Le Gentil de la Barbinais, que en esos momentos se encontraba en el lugar, quien planteó que la conspiración estaba acordada entre los llanistas, los que hicieron «correr la flecha» entre sus asentamientos llamando a la guerra. Dicha convocatoria fue descubierta cuando un falso eremita indígena, en palabras de Le Barbinais, que a pretexto de pedir limosna había juntado una gran cantidad de hierro para hacer lanzas, fue sorprendido en su engaño. Éste, luego de ser apresado y torturado, confesó todo lo que sabía de la proyectada rebelión, lo que le dio al gobernador los antecedentes y el motivo para lanzar una gran campaña de represión contra los indios que vivían en los distritos fronterizos situados al norte del Biobío. Pero la rebelión nunca llegó a ocurrir, lo que no obstó para que cinco prisioneros fueran ejecutados públicamente, descuartizados y exhibidos en los caminos que salían de Concepción. ${ }^{26}$

Para principios del siglo XVIII nada parecía imposible, pues ésta era al menos la segunda vez en sesenta años que los indios «domésticos» y otros que vivían al interior del reino se habían aliado con los habitantes de más al sur, por lo cual no sólo se ameritaba tomar medidas precautorias, como la prohibición de que los indios anduvieran a caballo, que Barros Arana calificó como una medida curiosa; sino reaccionar fuertemente ante esta amenaza, dando una señal poderosa respecto de la dureza con que se actuaría contra quienes pretendieran alzarse en armas, en una especie de reacción preventiva diseñada para producir temor entre los posibles rebeldes, quizás el mismo temor que ellos producían a los hispanocriollos.

\section{El miedo al «otro» en Chile central: los Aucas contra Santiago en 1723}

En marzo de 1723 los mapuches de los territorios fronterizos al río Biobío provocaron la muerte de dos capitanes de amigos y la salida de los colonos hispanocriollos de la Araucanía, a lo que siguió el cerco del fuerte de Purén y el comienzo de un alzamiento que involucró a parte importante de las parcialidades de dicho territorio. Por su parte los españoles,

25 Barros Arana, 1886, VI, 28-29.

26 De la Barbinais, 1728, 41. Agradezco a Jaime Valenzuela la traducción de este texto. 
encabezados por el gobernador Gabriel Cano de Aponte, movilizaron al ejército y a las milicias del reino con la intención de combatir dicha rebelión y evitar su extensión por Chile central. Ello motivó un sentimiento de gran preocupación en todo el reino, más aun cuando los eventos fueron demostrando que esta sería una situación que habría de prolongarse en el tiempo. En tal sentido, los encuentros directos se espaciaron y los mapuches parecían evitar el combate frontal, contentándose con erigirse en una fuerza amenazante y elusiva, situación que se mantuvo por todo el otoño y el invierno de ese año. ${ }^{27}$

En Santiago, en tanto, los hechos se precipitaban. Mientras las autoridades pedían apoyo militar y económico al virrey del Perú, parte de las milicias ya habían salido hacia el distrito penquista, así como las pocas tropas regulares que se encontraban en la capital. En sus calles, en tanto, se dejaban oír frecuentes noticias respecto de lo que ocurría en el sur e, incluso, de los temores de que la rebelión se hubiera extendido allende los Andes.

Se fue configurando así una visión de que la rebeldía indígena era más importante de lo que en una primera instancia se consideró y que este alzamiento podía replicar el de 1655 y ser aún más violento y destructivo, al involucrar a parte importante de la población originaria tanto del interior del reino como de sus fronteras. Las habladurías, mientras tanto, traspasaron las calles para arribar a las oficinas de los funcionarios de la monarquía. Así, el 13 de mayo de 1723 el cabildo de Santiago realizó una sesión extraordinaria para conocer una misiva enviada por el corregidor de la provincia de Cuyo. En ella se planteaba que en una fecha, al parecer cercana a la de la carta, se había recibido información de dos caciques amigos respecto del inminente movimiento de indios aucaes pampeanos y cordilleranos con la intención de atacar Mendoza y las otras ciudades cuyanas. ${ }^{28}$

Frente a esta sospecha el corregidor solicitaba que se le enviaran cien fusiles y carabinas a dicha urbe, que sólo contaba con cuarenta armas de fuego en mal estado y cuatrocientos habitantes varones para su defensa, lo que fue aprobado por el Cabildo, preocupado porque dichas noticias fueran verdaderas, con el consiguiente peligro que aquello implicaba no solo para las villas ultramontanas, sino para la propia Santiago, que de triunfar los indios quedaría amenazada por su flanco oriental y casi sin oportunidad de defenderse.

27 Casanova, 1987, 19 y siguientes.

28 CHCh, LI, 25. Acta del cabildo de Santiago de 13 de mayo de 1723. 
No obstante, dicha información era confusa y, en tal sentido, el temor de que tales ataques se concretaran crecía fuertemente y generaba numerosas interrogantes, sobre todo respecto de la cantidad de hombres que formaban las fuerzas enemigas, cuántos grupos étnicos y quienes concretamente estaban alzados y cuáles eran las verdaderas razones del supuesto ataque. ¿Se trataba acaso de la rama pampeana del alzamiento de la Araucanía? ¿O se estaba frente a un movimiento rebelde con características y demandas propias? Aunque tales preguntas eran casi imposibles de contestar, ellas recordaban las amenazas de ataque a Mendoza en 1658, aunque esta vez no hubieron caciques ni indios presos y sólo se conocieron informaciones de una supuesta agresión. Pero el problema con las noticias confusas era que prontamente podían convertirse en rumores, los que inmediatamente nacían con más de una versión.

De a poco el escenario rebelde se ampliaba, por lo cual se debían tomar medidas preventivas en los lugares donde éste todavía no se manifestaba y sobre todo en los que la posibilidad del mismo crecía exponencialmente, como lo era la ciudad de Concepción. De tal modo, en julio de 1723 el gobernador Cano de Aponte dictó providencias para impedir el tránsito de los indios en las noches y reeditó esa vieja prohibición de que se movilizaran a caballo luego de cierta hora o más allá de una distancia determinada de donde comenzaban su viaje. ${ }^{29}$ Pero hasta el momento, lo que parecía ser el mayor temor de la población santiaguina no había llegado a concretarse: esto era que la rebelión traspasara la frontera o los Andes y se extendiera por el valle central de Chile.

Aquello, sin embargo, pronto estaría por cambiar. El 20 de agosto de 1723 el corregidor de Chillán informó a Cano de Aponte, que:

me allo con 14 ianaconas presos en esta guardia a quienes estoi exsaminando i lo que e descubierto es estar conplicados con los de la tierra adentro siendo sus designios dar abanse a esta plasa y ciudad luego que la gente saliese al biage que tienen entendido egecute Vuestra Excelencia esta primabera cuia coligacion es general en toda esta jurisdicion dando prueba a esto el que desde que tengo presos a estos referidos se an uido dibersos yndios de las estancias y oi dia de la fecha me abisan se juntan en la cordillera de Alico y sus contornos a abiarse y armarse. ${ }^{30}$ 297-300

29 Archivo Nacional Histórico de Chile, Fondo Capitanía General (ANHCG), 390,

30 ANHCG, 489, 174. Carta del corregidor de Chillán don Domingo Beza al gobernador don Gabriel Cano de Aponte. Chillán, 20 de agosto de 1723. 
Al fin los temores se habían vuelto realidad. Los catorce presos, como antes, eran prueba viviente del alzamiento. Asimismo, la huída de otros de las estancias donde vivían y el aviso de la reunión de los conjurados en Alico se constituían como un escenario rebelde clásico, más aun cuando sólo cinco días más tarde el corregidor confirmará que tenía información de que más de cien indios se encontraban reunidos en aquel lugar. Mientras tanto, en Rere, Puchacay, Itata y en la propia Concepción el temor ante el alzamiento de los indios vivientes al interior del reino crecía, lo que llevó a que el cabildo penquista se opusiera a que los labradores que habitaban en sectores cercanos a la ciudad fueran enrolados, pues ello implicaba dejar desprotegida la campaña cercana a la urbe regional. ${ }^{31}$

Ante esto, tanto para la población santiaguina como para los funcionarios reales las preguntas que debían hacerse parecían obvias. ¿Estaba corriendo la flecha de la guerra más al norte?, ¿había alcanzado Santiago?, ¿quién o quienes la portaban? Por último ¿había indios o comunidades que se habían sumado al alzamiento? Y en ese caso ¿Quiénes eran los alzados en Chile central y cuándo atacarían?

Las respuestas llegaron cuando a fines de septiembre de 1723 el alcalde Gallardo Lísperguer recibió la denuncia de que un grupo de indios que residía en los parajes de Paine y Hospital, situados a 50 kilómetros al sur de la ciudad, preparaban un asalto contra ésta. Rápidamente Gallardo movilizó partidas de caballería que apresaron a los denunciados, los que fueron trasladados a la cárcel de la Real Audiencia para ser interrogados. Con autorización del gobernador, el edil asumió como juez de comisión y en vista de que las noticias parecían ciertas amplió la búsqueda de más implicados. Su pesquisa llevó a que más de ciento veinte indios de distintos sectores de los partidos de Santiago, Melipilla y Colchagua fueran apresados. La conmoción que dicha batida provocó, aumentó el temor de la población santiaguina y extendió la noticia por toda la región central.

A partir de las denuncias realizadas contra indios específicos y de los rumores que corrían por la ciudad, Gallardo se formó una visión del delito que intentaba evitar, pero también de quienes perseguía. En base a ello se elaboraron los interrogatorios, comenzando lentamente a formarse una suerte de versión oficial o, al menos, consensuada de lo que habría ocurrido. Tal versión fue recogida por algunos de los escritores de la época y aun cuando algunos, como Vicente Carvallo y Goyeneche, escribieron varias

31 León, 2002, 261-263. 
LUGARES (SUPUESTAMENTE) ALZADOS EN 1655 Y 1723

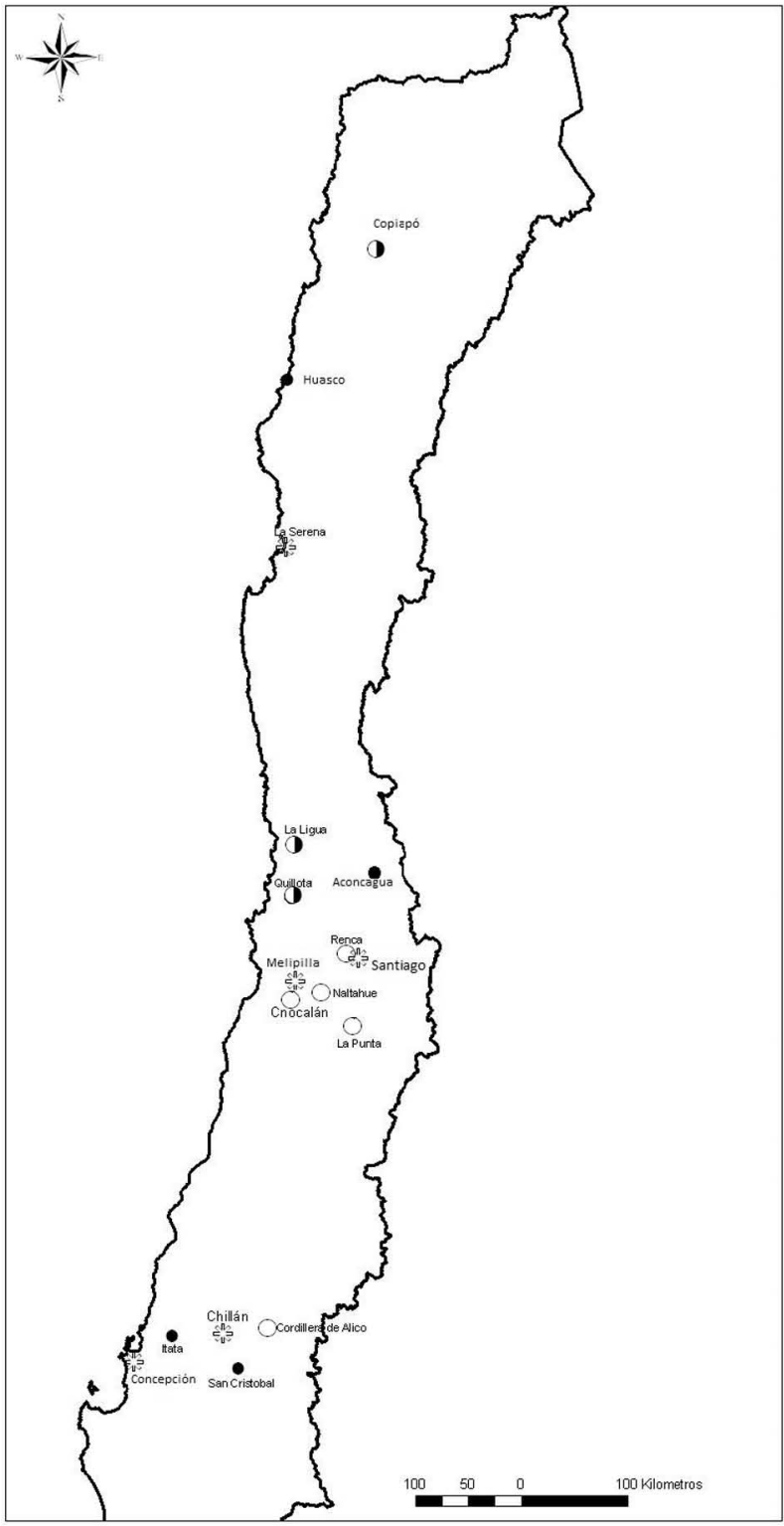

\section{Leyenda}

- Alzados en 1655

- Nlzados en 1723

- Alzados en 1655 y 1723

sny Ciudades o villas

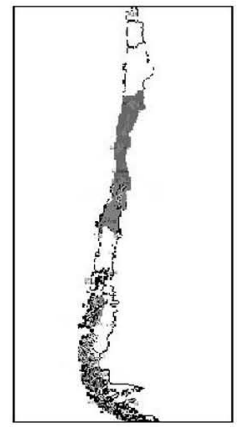

Datum Wgs84

Autor: Rodrigo Valdés 
décadas después de ocurridos los hechos, su texto expresa bien tanto las acusaciones contra los indios como las sospechas de la población capitalina. De hecho, esto lo hace aún más interesante, pues en este caso estamos frente a la construcción de un nuevo hito en la memoria del miedo al indio, que al parecer acompañaría a la sociedad chilena hasta bastante entrado el siglo XIX.

Según Carvallo, en la víspera del 4 de octubre de 1723, cuando se celebrara la fiesta de San Francisco de Asís y una vez que dos compañías milicianas de reciente formación salieran hacia la frontera, solapadamente y sin previo aviso los indios que habitaban las cercanías de la capital se dejarían caer sobre ella. Violencia y muerte era lo que esperaba a los habitantes de Santiago, especialmente a los hombres que quedaran allí; mientras tanto para las mujeres y niñas su destino sería el cautiverio, la humillación y el vejamen sexual. De tal modo que:

se levantó una voz vaga en aquella ciudad ( 3 de octubre de 1723), i en pocos momentos se difundió por toda ella que en los pagos de la Punta i Renca estaba campado un cuerpo considerable de insurjentes con designio de saquearla. Hubo en ella la más horrible confusión. Ni los eclesiásticos se eximieron de tomar las armas; i se pusieron salvaguardias en los monasterios de relijiosas para que no las incomodasen. Se envió una partida de jente armada de los vecinos i mercaderes a reconocer los contornos, i todo era turbación. ${ }^{32}$

Por su parte, Gallardo y sus hombres continuaban su tarea de traer nuevos sospechosos a la cárcel. Ese año la solemne fiesta de San Francisco, que incluía sacar al santo de su iglesia y pasearlo por la ciudad escoltado por el Cabildo, las cofradías y un numeroso grupo de fieles, fue suspendida y los fuegos artificiales fueron trocados por fusiles y pistolas. No sabemos, sin embargo, cuánto tiempo duró tal conmoción pero sí que en los días siguientes la sospecha se instaló sobre los inmigrantes mapuches que habitaban los distritos cercanos a la capital, pero también sobre el conjunto de los indígenas de Chile central, como bien lo expresó el cabildo capitalino en su sesión del 3 de octubre, en cuya acta quedó indicado que en la rebelión:

se han conspirado los indios encomenderos no solo de los partidos de Melipilla a la frontera, sino también los que se hallan en los valles de Quillota, la Ligua hasta Copiapó. ${ }^{33}$

32 CHCh, IX, 241-242. Vicente Carvallo y Goyeneche. Descripción Histórico-Jeográfica del reino de Chile.

33 CHCh, LI, 52. Acta del Cabildo de Santiago de 2 de octubre de 1723. 
El estado de las informaciones con que se cuenta y el hecho obvio de que el alzamiento no llegó a producirse, nuevamente imposibilitan saber positivamente los verdaderos alcances de la concertación rebelde o, incluso, si ella llegó a ocurrir alguna vez. No obstante, en el curso del proceso judicial surgió una gran cantidad de informaciones que, aun cuando algunas eran contradictorias entre sí, permiten analizar tanto las representaciones que los hispanocriollos y la sociedad colonial en general tenía respecto de los alzados, como la dinámica social y cultural de los indios rurales y principalmente la de los inmigrantes llegados de la «tierra adentro», quienes en Chile reeditaban parte de las instituciones de su suelo, aun cuando ahora las identidades etnoterritoriales estrictas daban paso a una relación en la cual el origen de cada indio era un dato más a considerar, pero no necesariamente el único. ${ }^{34}$

La propia carencia de estructuras parentales a las cuales recurrir, el hecho de tratarse de sujetos que llegaban solos o de pequeños grupos familiares, el estar en contacto permanente y cotidiano con una sociedad multiétnica como era la colonial y los conceptos que en ella se manejaban respecto de los migrantes, entre otros factores, explican que al menos para los hispanocriollos eran todos indios «de la tierra adentro». Por lo anterior, el pasar de ser conceptuado de indio «doméstico», fiel o yanacona a auca solo dependía de su comportamiento o, en este caso, de aquel que se les atribuyera.

Precisamente, las denuncias de unos indios contra otros, a quienes acusaron de juntarse por las noches a hablar en secreto, irse a lugares apartados para participar de «borracheras» y portar armas, dieron mérito para que fueran apresados. No sabemos la causa real de la denuncia, pero lo que queda claro es que probablemente nadie imaginó hasta donde llegaría aquello. Como fuera, las palabras de Clara Acacaya, una mujer de más de 50 años, natural de Tucapel y quien residía junto a su hija y su yerno, Pedro Lemullanca, en una estancia situada en Paine y de Juan de la Cruz, natural de Concepción y residente en la misma localidad, abrieron una marea de denuncias y acusaciones. En una declaración judicial fechada en 30 de septiembre de 1723, De la Cruz planteó que a fines de julio de ese mismo año había escuchado a Antón Pichunguala, de Tucapel, y a Pascual, un indio de Maquegua que supuestamente ostentaba el título de cacique, quienes:

34 Contreras, 2006, 19. 


\section{HUGO CONTRERAS CRUCES}

avian de yr a Aculeu a determinar la juntta y subirse al serro de Merungue al paraxe que llaman la huerta donde tenian tres mill y quatrocientas lanzas dispuestas y que hera menester endurezerlas para dar el asalto a la ciudad y matar a los españoles captibando las mugeres y llevando a la excelentisima señora governadora consigo para hazerla que les hiziese la chicha y que todos los yndios de la costa desde maule para aca se benian a junttar al dicho serro de Merumgue para la faccion referida... y que demas de ello esperaban tres parcialidades de yndios que pasaban por el Portillo de la otra banda de la cordillera que benian a cargo del hijo del casique Ayllacuriche para allanar toda la tierra que benian conquistando por la otra banda. ${ }^{35}$

A tal relato se le agregarían o sacarían elementos por parte de acusadores, testigos y acusados, lo que derivaría en una rápida complejización de la historia y la recurrencia a una serie de detalles que aun cuando fueran difíciles de congeniar, irían construyendo una imagen de la rebelión pero a su vez del temor de los hispanocriollos. La presencia, por ejemplo, de un hijo de Aillacuriche como líder de una fuerza militar auca venida desde la Pampa, más allá de resultar casi imposible, traducía el miedo atávico a la guerra mapuche personificada en el vástago de aquel lonko que encabezó la resistencia antiespañola en la Araucanía medio siglo atrás y quien había sido ejecutado a traición en $1674 .{ }^{36}$

Por su parte, hubo acusados que aportaron nuevos detalles, que lejos de mejorar su situación judicial, la iban haciendo cada vez peor. Sobre todo cuando algunos insistieron en que la conspiración estaba extendida por gran parte del reino y que la llamada a la rebelión venía corriendo de sur a norte. Así lo relató Agustín Sacalagua, natural de Chocalán, quien declaró que al ir a coger unas yeguas cerca de su pueblo, se encontró con cinco indios a quienes calificó como aucaes, uno de los que le ofreció:

una cosa como una mano blanca por que el aforro paresia de pellegillo poco mas prietto que el papel, y ensima como un tafettan colorado y yendola a coger le dio horror y no la quiso tomar por que le paresio ser mano de gentte. ${ }^{37}$

Dicho sujeto, llamado Juan, lo amenazó diciéndole que si no tomaba el despojo, que era precisamente la llamada «flecha de guerra», lo mataría

35 ANHRA, 1616, 3, 146-146 v. Declaración de Juan de la Cruz. Santiago, 2 de octubre de 1723.

36 Barros Arana, 1885, V, 190-191; Obregón y Zabala, 2009, 7-32. Luego de la ejecución de Aillacuriche su asentamiento fue atacado por el ejército real y todos sus integrantes fueron esclavizados y repartidos por distintas partes del reino.

37 ANHRA, 1616, 3, 167-167 v. Confesión de Agustín Sacalagua. Santa Inés, partido de Rancagua, 22 de septiembre de 1723. 
como a los españoles, pues era winka como lo eran ellos. Seguidamente agregó que:

benia de Maquegua con la flecha que hera una mano que alli traya, y que la avia venido corriendo por todos los partidos de Maule y Colchagua y que avia pasado por Lora y por los Coypos; y que pasaba adelante con la dicha flecha hazta la Ligua y Choapa, para que quando volviese estubiesen todos los yndios combocados para dar el asaltto a esta ciudad y a ttodas las estancias desde Choapa asta la Conzepcion. ${ }^{38}$

Tal conversación se desarrolló en castellano, que era el idioma en que hablaba Sacalagua, y aunque los aucaes le hablaron en mapudungun, el confesante declaró que no entendió lo que le decían, ni tampoco pudo afirmar adónde se dirigieron luego de su encuentro. Tal testimonio judicial sorprende por la certeza de los detalles, más aun cuando Sacalagua fue apresado días antes que en Santiago se conociera la denuncia hecha por Acacaya. En este caso, había sido el teniente de corregidor de Melipilla quien había prendido al indio.

En esta declaración, el elemento que se transformaba en central era la presencia física de la «flecha de la guerra», que en esta oportunidad era una mano cercenada envuelta en un paño. Nuevamente las instituciones guerreras mapuches se hacían presentes y con ello el temor tendía a aumentar, pues en momentos de conflicto no había otra forma de convocar a los guerreros que a través de este mecanismo. Si antes había sospechas de que este tipo de elementos se trasportaba secretamente, en estos momentos y a pesar de que Juan y sus camaradas nunca llegaron a ser atrapados, las autoridades sabían bien qué y a quienes buscar.

Pero aquello no era todo, pues Sacalagua y algunos de los confesantes afirmaron haber participado de reuniones en que se había planificado el asalto a Santiago y la destrucción de las haciendas cercanas a la urbe. La dinámica de las mismas, que fueron significadas como cagüintunes por los alcaldes y oidores que tomaron parte en el juicio, no requirieron mayor explicación para los indios, aunque al menos a uno hubo que explicarle que era un alzamiento. Por parte de los acusados había distintas versiones sobre lo sucedido en dichas reuniones, algunas bastante similares a lo expresado por Carvallo y otros cronistas de la época, como la dada por Juan Perquecheuque, un indio de Toltén, quien declaró que fue engañado al cerro Merungüe:

38 ANHRA, 1616, 3, 167 v. Confesión de Agustín Sacalagua. Santa Inés, partido de Rancagua, 22 de septiembre de 1723 . 


\section{HUGO CONTRERAS CRUCES}

y alli fue el cavyntun y hallo mas de seiscientos yndios y el que tenia la flecha hera un yndio viexo chileno el qual era toqui y que no save su nombre el qual era alto barbon medio amulatado, y que alli estavan rebueltos yndios paysanos y chilenos y anaconas, y que tendrian mas de mill lanzas de culeu todas con hierros... y que sus designios eran hazer campeada en esta tierra y entrar en este pueblo el dia de san francisco a media noche,...y el dicho caguintum se trato de como el dia citado havian de quemar todas las casas de este pueblo, y conventos y matar todos los cavalleros y ombres y dexar las mugeres y llevar a la señora governadora para la cosina. ${ }^{39}$

Otros indios, argumentaron que solo se trataba de reuniones sociales, pero en ningún caso se había planificado allí un alzamiento. Independientemente de aquello, en todos los relatos se podían encontrar elementos comunes como el consumo de alcohol y el baile, en ocasiones en torno a un árbol de canelo, como habría sucedido en el Principal de Pirque, o bien enarbolando una bandera roja, según declararon los acusados provenientes de Chocalán. En ellas aparecían participando indios provenientes de distintos lugares del reino, generalmente cercanos a los lugares de las juntas, aun cuando no faltaron las declaraciones que afirmaban haber visto a sujetos provenientes de La Ligua y Choapa, así como a indios de «arriba» o de la «tierra adentro». Para sus acusadores, en cambio, esas fiestas no tenían otro objetivo más que planificar la rebelión y concertarse para ejecutar el próximo paso, que era irse al cerro Merungüe, que uno de los testigos situó en el sector de Naltahua, ubicado a más de 40 kilómetros al suroeste de la capital.

Los rumores de alzamiento pusieron de manifiesto el temor real de que lo que se decía fuera cierto, lo cual parecía confirmarse con el apresamiento de más de un centenar de sujetos y sus declaraciones. Pero ese miedo no era neutro, sino que específicamente se dirigía hacia un «otro», el indio, que no solo se consideraba legalmente distinto de los hispanocriollos, sino un sujeto que por su propia naturaleza estaba permanentemente en entredicho, más aun si era un inmigrante reciente. La desconfianza elitaria y monárquica hacia la «plebe», representada como levantisca y ruidosa, pareció pasar a segundo plano en estos momentos, pues si bien los indios y, sobre todo quienes estaban asociados a la ciudad podían identificarse con la abigarrada multitud popular, en esta ocasión se hizo un verdadero esfuerzo por separar a unos de otra, más todavía si los acusados provenían de aislados parajes rurales o de los territorios situados al sur del Biobío.

39 ANHRA, 1616, 3, 162. Confesión de Juan Perquecheuque. Santiago, 2 de octubre de 1723. 
Si el «otro» era quien participaba de un universo distinto al español, lo que inmediatamente lo marginaba de la cultura y formas sociales hispanas, entonces los indios inmigrantes eran la representación misma de esto. Descontextualizados de su realidad cultural parecía que solo mudaban sus costumbres o sus nombres, como lo hizo Pedro Lemullanca, que cambió su patronímico a Donoso, como un signo exterior de su transformación. Se hacían o mejor dicho se decían cristianos sólo para vivir sin problemas con la Iglesia y con la sociedad española, pero en el fondo seguían siendo tan «paganos» como el día en que salieron de su tierra. Por esto es que a pesar de que casi desde los comienzos mismos de la colonización europea de Chile los migrantes mapuches forzados o voluntarios habían convivido con los colonizadores, los indios cuscos que los acompañaban, con negros esclavos y, más tarde, con los innumerables sujetos mezclados propios de la sociedad colonial, cada vez que un indio fronterizo o de la Araucanía se internaba en Chile se renovaba la presencia y la representación de aquellos que venían desde lugares ignotos, que portaban otras costumbres, que eran infieles o estaban pobremente cristianizados y de los cuales se debía desconfiar.

Por lo anterior es que no es extraño que entre los principales acusados se encontrara un grupo de «indios de arriba». En tales sujetos el alcalde Gallardo concentró sus interrogatorios. Particularmente, los inmigrantes que residían en el valle de Aculeo fueron apresados durante la última semana de septiembre de 1723 gracias a la denuncia de Juan de la Cruz, quien señaló que los alzados eran:

Pedro yndio yerno de Clara yndia de arriva Antton Pichumguala hermano de la dicha yndia Clara Anton Botello..., Alonso yndio...Augustin...Panchillo yndio..., otro yndio guaynita que solo le conoce por Guente Roza...otro yndio llamado Panchillo...que todos los sobredichos son yndios de arriva y Pazqual yndio de Maquegua que dizen ser casique...Ygnacio yndio de arriva...y que el yndio Pedro yerno de la Clara tenia en su compañia al yndio Alonso y a Dionisio y Sevastian yndios de arriba. ${ }^{40}$

Mientras tanto, desde otros lugares siguieron llegando prisioneros a la cárcel de la Real Audiencia, entre los que se contaban más «indios de arriba» y algunos del partido de Melipilla, situado al sur poniente de Santiago. De hecho, quienes eran encomendados, como Agustín y Carlos Sacalagua, que en definitiva fueron los únicos que declararon haber visto la «flecha de

40 ANHRA, 1616, 3, 145-145 v. Declaración de Juan de la Cruz. Santiago, 2 de octubre de 1723. 
la guerra» y tenido contacto con sus portadores, bien podrían haber sido «contaminados» por los aucas, convirtiéndose ellos mismos en alzados y, por lo tanto, participes de la naturaleza fiera, embustera y traidora de los primeros.

Por su parte, algunos de los acusados comprendiendo el mecanismo que los hacía sospechosos, sacaron a relucir su larga permanencia en el territorio de Chile, sus conexiones familiares o sociales y su fe cristiana. Unos se declararon amigos de los españoles, mientras que otros apelaron al uso de expresiones cotidianas como prueba de su extensa residencia, pero todos quienes utilizaron estos argumentos insistieron en no tener ninguna razón para alzarse. Juan Carilab, un indio originario de Purén, de 70 años, declaró: «...para que avia de cojer la flecha contra los españoles quando los estaba sirviendo desde el tiempo del señor governador don Joseph Garro...». ${ }^{41}$ Palabras que remitían a las últimas décadas del siglo XVII, a lo que Carilab agregó (en el entendido que De la Cruz, su acusador, había indicado que él había hecho una «borrachera» en su casa), que efectivamente había realizado una junta con sus amigos, pero que ésta sólo tenía como objetivo «holgarse». Además, ella había sido hecha en un día de fiesta y exento de laborar, que era el de San Juan, apelando así al calendario festivo católico. Palabras, de todos modos, que podrían estar sujetas a más de una interpretación, pues por esa misma fecha se celebraba el solsticio de invierno, momento de especial significación mágico-religiosa para los mapuches, aunque esto no fue tomado en cuenta por sus interrogadores.

Por su parte, Pedro Curagüeno, que provenía del mismo asentamiento que el anterior, manifestó que:

el a muchos tiempos que esta en esta ciudad...y que no era indio resien venido,...y que aqui le conosen todos y que a sido leal a su Magestad...que vino a esta ciudad en tienpo de peluca que era el señor don francisco Ybañes governador y capitan general que fue deste Reyno. ${ }^{42}$

Eso remitía al menos a quince años atrás, lo cual según Curagüeno probaría su hombría de bien y, por extensión, su inocencia. En su concepto, entre más se alejaba en el tiempo su llegada a Chile, más quedaba atrás la imagen del auca o del «otro», para integrase a la comunidad rural local y a la cristiandad.

41 ANHRA, 1616, 3, 152 v.-153. Confesión de Juan Carilab. Santiago, 2 de octubre de 1723. 42 ANHRA, 1616, 3, 151. Confesión de Pedro Curagüeno. Santiago, 2 de octubre de 1723. 
Por el contrario, viendo a estos sujetos en su contexto social y económico, si bien dichas palabras podían ser ciertas, al mismo tiempo lo eran otras, muchas veces pronunciadas por ellos mismos, que los mostraban ante los jueces como hombres y mujeres carentes de bienes materiales y de poco arraigo en la tierra, lo que se traducía en un continuo transitar de hacienda en hacienda en busca de trabajo, aunque también esto podía ser motivado por la huída de la justicia. El propio Juan de la Cruz no escapaba a esta dinámica que, en general, era extensiva a parte importante de los migrantes de la Araucanía. Al identificarse manifestó ser ladino en lengua castellana y natural de Concepción y que:

a dos años que bajo a esta tierra con Helena yndia su muger criada de don Gabriel de la Vega y que a servido a don Barttolome de Prado, de donde cumplido el tiempo de su consierto se fue a servir a don Francisco Dias Pimienta, y de ay paso a servir a los padres de San Juan de Dios en la estancia de Payne a donde a estado sirviendo. ${ }^{43}$

En dos años, De la Cruz había estado trabajando como peón en tres haciendas. Seguramente en la primera cumplió un año de servicio, que era el tiempo normal de los asientos de trabajo de los peones rurales; mientras que en las otras es imposible saber cuántos meses estuvo en las mismas, pero de todas maneras no alcanzó a enterar un año. De la última de ellas, el indio declaró haberse ido por temor a que los alzados lo mataran, reacción que tampoco parece extraña y que si se aplicó en esta oportunidad no hay razón para que éste y otros migrantes, sobre todo aquellos acusados de algún delito, no la usaran cuando lo consideraran pertinente.

Del punto de vista de las autoridades civiles y eclesiásticas, el transitar de los indios tenía consecuencias evidentes en su cristianización, así como en la posibilidad de trasladar sus costumbres bárbaras a nuevos parajes, donde se encontraban con otros migrantes, con indígenas locales y con mestizos y españoles pobres que residían en dichos espacios. En periodos de crisis, tales desplazamientos reeditaban las clásicas imágenes de los indios que llevaban «la flecha» de lugar en lugar, sin detenerse más que algunos días o semanas en cada uno, como en algún momento se acusó a Juan Ingaigüieno en los ya lejanos días de 1660, que hemos analizado en páginas anteriores.

43 ANHRA, 1616, 3, 144 vta-145. Declaración de Juan de la Cruz. Santiago, 2 de octubre de 1723. 
Más todavía, los argumentos esgrimidos por los indios parecían no ser suficiente prueba de lealtad ni de un bien acabado proceso de cristianización, pues junto con quienes ya estaban asentados en el reino se encontraban muchos nuevos migrantes, que se concebían como aun en contacto con sus parientes del sur del Biobío y todavía sujetos a sus costumbres. En ese sentido, la reedición de la figura arquetípica del «otro» se hacía más fuerte en ellos, más aun cuando algunos no habían adoptado los rudimentos básicos de la cultura española. Así, al menos dos de los detenidos junto a Curagüeno en el partido de Aculeo tuvieron que ser interrogados mediante un intérprete pues solo hablaban mapudungun. A éstos en el expediente se les calificó como bozales, epíteto generalmente usado para los esclavos africanos recién introducidos a los territorios americanos y que no conocían ni el idioma castellano ni la religión cristiana. Ese fue el caso de Alonso, asimismo de Purén, quien hacía dos años que había llegado a residir al Principal de Pirque. Mientras tanto, Andrés hacía cuatro años que había venido desde la Imperial, pero todavía no hablaba un castellano medianamente inteligible. ${ }^{44}$ Ambos declararon no saber nada del supuesto alzamiento y aun más, Andrés destacó que él no tenía amistad ni se reunía socialmente con los demás indios de la estancia de Hospital, muchos de ellos inmigrantes, pues a diferencia de él estos serían borrachos.

Lo anterior, sumado a la falta de conexiones familiares o sociales estables entre los inmigrantes más recientes, que generalmente se asentaban con otra familia rural; su gran facilidad para moverse por la geografía del valle central e, incluso, la rapidez con que cambiaban de trabajo, cuestiones estas dos últimas que podían concebirse como generales para el conjunto de los migrantes mapuches, más aun cuando estaban exentos de ser encomendados y de tributos, los convirtió a los ojos de las autoridades en las cabezas visibles de la supuesta conspiración para destruir Santiago. ${ }^{45}$

Eran ellos y no los indios de las comunidades originarias de Chile central, en quienes se concentró la persecución, la que no terminó pasada la coyuntura militar fronteriza o disipados los temores en la capital, pues parte importante de los mismos fueron mantenidos en la cárcel por largo tiempo. Para ciertas autoridades dicho lugar parecía ser el mejor para aquellos indios, pues al neutralizar su capacidad de moverse y comunicarse con otros se le ponía coto, al menos de manera simbólica, al temor y la desconfianza generada por su transitar libre. Ésta era una pretensión sin sentido,

44 ANHRA, 1616, 3, 149-150.

45 Contreras, 2006, 11 y ss. 
pero explicable por la sensación de miedo que recorrió tanto a la población santiaguina como a sus autoridades y de la cual el proceso contra los supuestos alzados es una de las huellas más visibles.

\section{CUADRO 1}

PRINCIPALES IMPLICADOS EN EL ALZAMIENTO CONTRA SANTIAGO (1723)

\begin{tabular}{lllll} 
Nombre & Edad & Origen & Residencia & $\begin{array}{l}\text { Permanencia en } \\
\text { Chile central }\end{array}$ \\
\hline Clara Acacaya & 50 años & Tucapel & Angostura de Paine & No consta \\
Juan de la Cruz & No consta & Concepción & Estancia de Paine & 2 años \\
Pedro Lemullanca & 30 años & Purén & Angostura de Paine & 10 años \\
Anton Pichunguala & No consta & Tucapel & Angostura de Paine & No consta \\
Anton Botello & No consta & «De arriba» & No consta & No consta \\
Alonso & 25 años & Purén & Principal de Pirque & 2 años \\
Agustín & No consta & «De arriba» & Angostura de Paine & No consta \\
Panchillo & No consta & «De arriba» & Angostura de Paine & No consta \\
Guente Roza & «uainita» & «De arriba» & Angostura de Paine & No consta \\
Panchillo & «uainita» & «De arriba» & No consta & No consta \\
Pascual & No consta & Maquegua & Aculeo & No consta \\
Ignacio & No consta & «De arriba» & No consta & No consta \\
Dionisio & No consta & «De arriba» & Angostura de Paine & No consta \\
Sebastián Levipan & 24 años & San Cristóbal & Angostura de Paine & «hace poco» \\
Andrés & 30 años & Imperial & No consta & 4 años \\
Pedro Curagueno & 40 años & Purén & Aculeo & 10 años aprox. \\
Juan Carilab & 70 años & Purén & Principal de Pirque & 25 años aprox. \\
Juan Maripañi & 30 años & San Cristóbal & Nuñoa & No consta \\
Pedro & 19 años & Concepción & Chuchunco & No consta \\
Juan Perquecheuque & 23 años & Toltén & No consta & No consta \\
Carlos Sacalagua & 30 años & Chiñihue & Popeta & \\
Agustín Sacalagua & 27 años & Chiñihue & Popeta & \\
Lorenzo Collipangui & 74 años & Melipilla & Melipilla & \\
Ignacio Soria (mestizo) & 40 años & Viluco & Naltahua & \\
Andrés Donoso & 40 años & & No consta & \\
& & & & \\
& & & & \\
& & &
\end{tabular}

Fuente: ANHRA, 1616, 3.

Algunos años pasaron, la pista de los inculpados se perdió entre los legajos de archivo y en su propia y anónima vida; sin embargo, desde Madrid se pidieron noticias de cómo había concluido la situación, más aún cuando el gobernador Cano de Aponte había acordado la paz con Vilumilla y los demás jefes rebeldes y se había realizado un parlamento general en 
HUGO CONTRERAS CRUCES

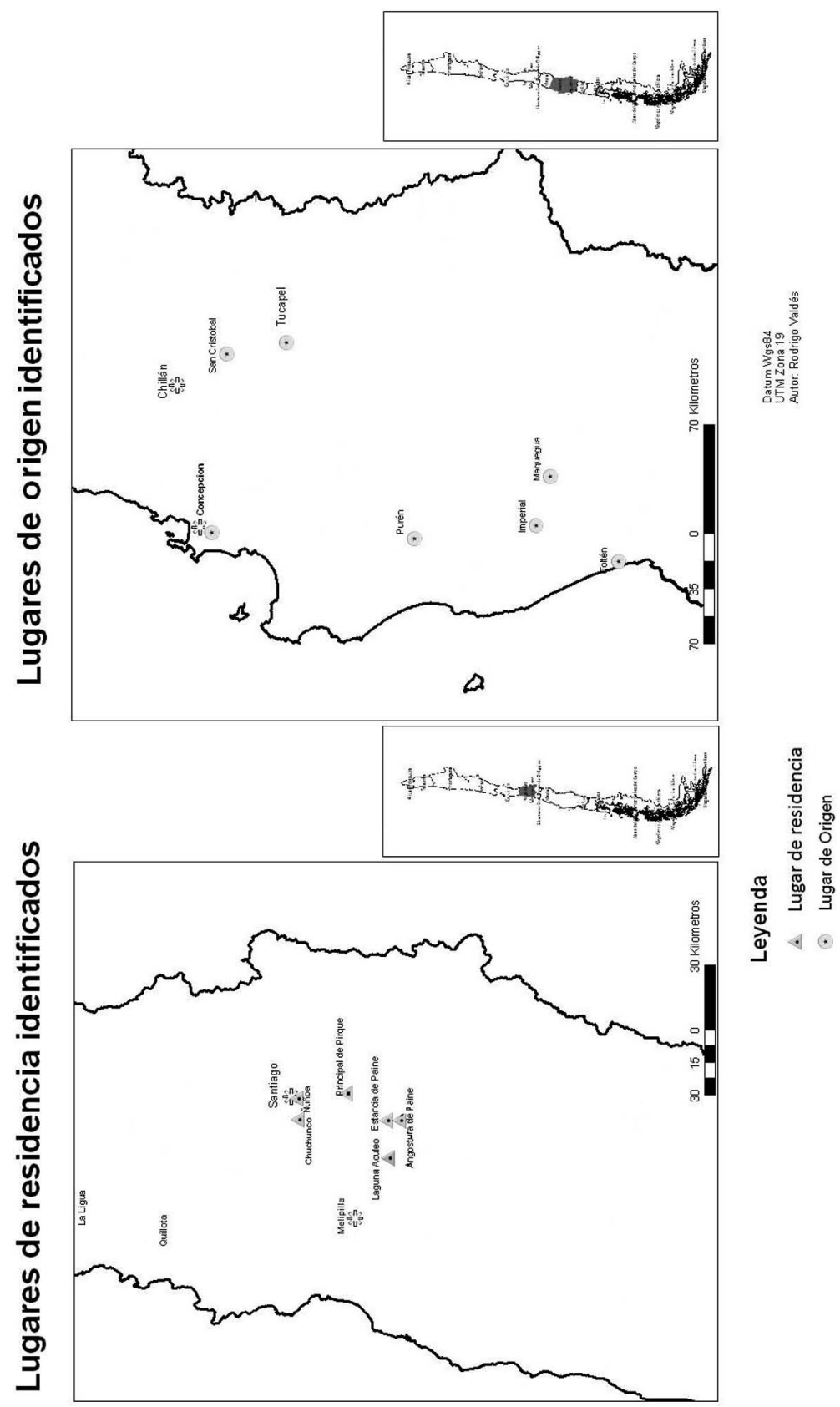


1726. De los informes enviados desde Chile se concluyó que el proceso, en términos judiciales, no había probado suficientemente la culpabilidad de los imputados, pero también que a más de cuatro años que la sumaria había concluido todavía había un número indeterminado de indios presos. Gracias a una petición de la Real Audiencia de Santiago, el rey Felipe V dictó una real cédula para liberar a los últimos prisioneros, que aunque tardía no podía ser sino justa y en la cual criticó en duros términos al alcalde Gallardo, pues él y sus tenientes:

fueron prendiendo, tan sin reflexión, que llegaron a tener en la cárcel más de ciento y veinte [indios] y[...] — continua el rey refiriéndose a lo actuado por la Real Audiencia- [...]reconociendo los clamores de estos pobres en las visitas de los sábados, pedisteis relación de todos los autos y viendo lo injusto de la prisión de más de setenta, los hicisteis soltar, sin más motivo que el que persuadía su justicia. ${ }^{46}$

\section{Conclusiones}

El miedo al «otro», en este caso a los indios inmigrantes de la Araucanía, a los cuales se les calificaba rápidamente como aucas, tenía una larga historia en la sociedad colonial de Chile. Ella, sin embargo, no ha sido reconstituida todavía por la historiografía, que ha considerado que muchos de los hechos que permiten hacer relucir los sentimientos de temor y angustia frente al «otro», en realidad sólo fueron habladurías, temores infundados o exageraciones. No obstante, dicho miedo iba más allá de una sensación personal sin manifestaciones factuales, para convertirse en un temor colectivo que cruzaba social y políticamente a los integrantes de la sociedad colonial. Según Jean Delumeau, entre el conjunto de temores del hombre moderno, uno de los más destacados era precisamente el miedo a aquel que no participaba de un universo conocido y compartido, aquel que venía de tierras extrañas, con un idioma distinto y otra religión. En este caso eran, precisamente, los inmigrantes mapuches de la Araucanía quienes mejor representaban aquella figura.

Pero el miedo no era una cuestión solamente episódica. Por el contrario, si bien éste se mostraba en toda su crudeza en momentos de crisis, en general permanecía latente en las poblaciones coloniales y se transmitía de generación en generación. En ese contexto, el alzamiento general de 1655

46 Fuentes para la Historia del Trabajo en el reino de Chile, II, 84. Real Cédula sobre la libertad de algunos indios. 8 de julio de 1728 . 
fue uno de los hitos más importantes en la constitución de una verdadera memoria del miedo, en la medida que la actividad rebelde traspasó la línea fronteriza y se enseñoreó de los partidos de Concepción, Chillán e Itata.

La desconfianza y la conciencia del peligro inminente atravesaban el reino y las denuncias o las informaciones contra supuestos alzados se hicieron sentir cerca de Santiago. De ellas sólo se ha conservado documentación histórica concerniente a un par de casos. En ambos se mencionan la huida o el apresamiento de otros alzados, imaginarios o reales, lo que demostraría que estos hechos eran mucho más importantes de lo que sabemos o de lo que la historiografía nos ha mostrado.

El temor, a su vez, se alimentaba de los rumores que corrían en época de crisis, pero también de la serie de elementos que cada vez que se apresaba o se sospechaba de un indio salían a relucir. Éstos formaban parte de la dinámica propia de la guerra mapuche e incluían el viaje de la «flecha de la guerra», la realización de «borracheras» rituales y la concentración de los rebeldes en un punto en particular, desde donde comenzarían las hostilidades.

Todo lo anterior fue, precisamente, lo que encontraron los funcionarios monárquicos en distintos lugares de los partidos de Santiago y Melipilla en septiembre de 1723. En dichos territorios, poblados tanto por indios locales como por inmigrantes, se creyó descubrir y quizás efectivamente se hizo, una rebelión que tenía por objetivo destruir Santiago. Dicho ataque sumiría a la ciudad y sus habitantes en un caos, donde los hombres serían muertos y las mujeres cautivadas, mientras que los edificios serían quemados. El ataque había concertado a una gran cantidad de indios locales, de aucas e, incluso, a una columna indígena venida desde las Pampas. Esto llevó a más de ciento veinte de ellos a la cárcel.

Dichos sujetos dieron una gran cantidad de informaciones que por el nivel de detalle y por la forma en que fueron interrogados permiten pensar que, al menos entre los propios indios la posibilidad del alzamiento era más grande que los rumores que la rodeaban. Nunca sabremos si lo anterior fue así o no, sin embargo, en el expediente se revelaron todos los temores de los españoles y los elementos que en juicios e informaciones anteriores habían aparecido como los indicadores de la rebelión volvían a estar presentes aquí. En tal sentido, el supuesto alzamiento de Chile central en 1723 era un hito más, pero de primer orden, para seguir construyendo el miedo al «otro» y su memoria.

Recibido el 07 de febrero de 2012

Aceptado el 17 de octubre de 2012 


\section{Bibliografía}

Amunátegui, Miguel Luis: Los precursores de la independencia de Chile, Santiago, Imprenta Barcelona, 1910, II vols.

Barros Arana, Diego: Historia Jeneral de Chile: IV-V-VI vols., Santiago, Rafael Jover, 1885-1886.

Casanova, Holdenis: Las rebeliones indígenas del siglo XVIII, Temuco, Ediciones Universidad de la Frontera, 1987.

Contreras, Hugo: «Siendo mozeton o güeñi salio de su tierra para vivir entre españoles. Migración y asentamiento mapuche en Chile central durante el siglo XVIII, 1700-1750», Historia Indígena 9, Santiago, 2006, 7-32.

De la Barbinais, Le Gentil: Nouveau Voyage au Tour du Monde, Amsterdam, Pierre Mortier, 1728.

Delumeau, Jean: El miedo en Occidente (siglos XIV-XVIII): una ciudad sitiada, Madrid, Taurus, 2002.

Giudicelli, Christophe: «Pacificación y construcción discursiva de la frontera. El poder instituyente de la guerra en los confines del Imperio (siglos XVIXVII)», en Lavallé, Bernard (ed.), Máscaras, tretas y rodeos del discurso colonial en los Andes, Lima, IFEA-PUCP, 2006, 157-176.

Hanisch, Walter: «Esclavitud y libertad de los indios de Chile», Historia 16, Santiago, 1981, 5-60.

Jara, Álvaro: Guerra y Sociedad en Chile, Santiago, Editorial Universitaria, 1971.

Jara, Álvaro: Los asientos de trabajo y la provisión de mano de obra para los noencomenderos en la ciudad de Santiago, 1586-1600, Santiago, Universidad de Chile, 1959.

León, Leonardo: «Real Audiencia y bajo pueblo en Santiago de Chile colonial: 1750-1770», en Valenzuela, Jaime (ed.), Historias Urbanas, Santiago, Ediciones Universidad Católica de Chile, 2007, 67-90.

León, Leonardo: «Mestizos e insubordinación social en la frontera mapuche de Chile, 1700-1726», en Retamal, Julio (coord.), Estudios Coloniales II, Santiago, Editorial Biblioteca Americana, 2002, 207-280.

Mellafe, Rolando: Historia social de Chile y América. Sugerencias y aproximaciones, Santiago, Editorial Universitaria, 1986.

Obregón, Jimena y Zavala, José Manuel: «Abolición y persistencia de la esclavitud indígena en Chile colonial: estrategias esclavistas en la frontera araucano-mapuche», Memoria Americana 17, Buenos Aires, 2009, 7-32.

O'Phelan, Scarlett: «La construcción del miedo a la plebe en el siglo XVIII a través de las rebeliones sociales», en Rosas, Claudia (ed.), El miedo en el Perú, siglos XVI al XX, Lima, Fondo Editorial PUCP, 2005, 123-138.

Pino, Fermín y Lázaro, Carlos (Coords.): Visión de los otros y visión de sí mismos, Madrid, Consejo Superior de Investigaciones Científicas, 1995. 


\section{HUGO CONTRERAS CRUCES}

Ruiz, Carlos: «Insurrecciones Indígenas en Chile Central, 1598-1825», Alamedas 6, Santiago, 1999, 80-94.

Rosas, Claudia (ed.): El miedo en el Perú, siglos XVI al XX, Lima, Fondo Editorial PUCP, 2005.

Salinas, René: «Fama pública, rumor y sociabilidad», en Aránguiz, Horacio (ed.), Lo público y lo privado en la historia americana, Santiago, Fundación Mario Góngora, 2000, 133-154.

Todorov, Tzvetan: La conquista de América: el problema del otro, México D. F., Siglo XXI, 1987.

Valenzuela, Jaime: «Revisitando el "indigenismo" jesuita: en torno a los "bárbaros" de Arauco, la guerra y la esclavitud mapuche en el siglo XVII», en Chamorro, Graciela, et al., Fronteiras e identidades: Encontros e desencontros entre povos indígenas e missões religiosas, Sao Paulo, Nhanduti editora, 2011, 61-79.

Valenzuela, Jaime: «Esclavos mapuches. Para una historia del secuestro y deportación de indígenas en la colonia», en Gaune, Rafael y Lara, Martin (eds.): Historias de Racismo y Discriminación en Chile, Santiago, Uqbar Editores, 2009, 225-260.

Valenzuela, Jaime: «El terremoto de 1647: experiencia apocalíptica y representaciones religiosas en Santiago colonial», en Jaime Valenzuela (ed.), Historias Urbanas, Santiago, Ediciones Universidad Católica de Chile, 2007, 28-65.

Videla, Marisol: «El impacto de la mano de obra migrante mapuche en las haciendas de Maule y Concepción, 1716-1782», en Retamal, Julio (coord.), Estudios Coloniales III, Santiago, Universidad Andrés Bello, 2004, 285-313.

Weber, David: Bárbaros. Los españoles y sus salvajes en la era de la Ilustración, Barcelona, Crítica, 2007.

Zapater, Horacio: «Cuyo en 1658, amenaza de asalto de tribus indígenas aliadas», en Silva, Osvaldo, et al., Encuentro de Etnohistoriadores, Santiago, serie Nuevo Mundo Cinco Siglos 1, 1988, 34-52.

Zavala, José Manuel: «La visión hispana de los "indios enemigos" del reino de Chile durante el siglo XVIII, el caso de la rebelión de 1723», en González Cruz, David (ed.), Extranjeros y enemigos en Iberoamérica: la visión del otro. Del Imperio Español a la Guerra de la Independencia, Madrid, Sílex Ediciones, 2010, 287-303. 